\title{
Avaliação de políticas públicas de esporte: o caso do Plano Brasil Medalhas 2016
}

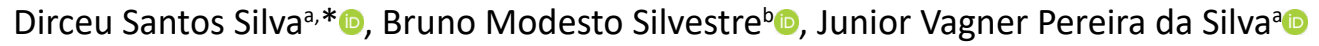

\section{Keywords:}

Políticas públicas;

Esportes;

Avaliação;

Legislação.

\begin{abstract}
O objetivo foi analisar o Plano Brasil Medalhas 2016 (PBM) a partir da avaliação por eficácia, eficiência e efetividade social. Trata-se de uma pesquisa descritiva-analítica, com abordagem qualitativa e inferência dos dados a partir da análise de conteúdo. Os resultados indicam que o PBM não foi eficaz, pois não alcançou o objetivo proposto de transformar o Brasil em uma potência olímpica. O PBM não foi eficiente, por aumentar o volume de recursos públicos para o esporte de alto rendimento e não atingir os resultados esperados no quadro de medalhas. No que diz respeito a efetividade social, o PBM não impactou na consolidação do Sistema Nacional de Esporte.
\end{abstract}

\section{RESUMO}

The aim was to analyse the 2016 Brazil Medals Plan (BMP) based on the evaluation for effectiveness, efficiency and social effectiveness. It is a descriptive-analytic research, with a qualitative approach, and inferring the data from the content analysis. The results indicate that the BMP was not effective, since it did not reach the proposed goal to transforming Brazil into an Olympic power. The BMP was not efficient because it increased the volume of public resources for high performance sports and did not achieve the expected results in the medal table. With regard to social effectiveness, BMP no impact in the consolidation of the National Sport System.

\section{RESUMEN}

El objetivo fue analizar el Plan Brasil Medallas 2016 (PBM) a partir de la evaluación por eficacia, eficiencia y efectividad social. Se trata de una investigación descriptiva-analítica, con enfoque cualitativo e inferencia de los datos a partir del análisis de contenido. Los resultados indican que el PBM no fue eficaz, ya que no alcanzó el objetivo propuesto de transformar a Brasil en una potencia olímpica. El PBM no fue eficiente, por aumentar el volumen de recursos públicos para el deporte de alto rendimiento y no alcanzar los resultados esperados en el cuadro de medallas. En lo que se refiere a la efectividad social, el PBM no impactó en la consolidación del Sistema Nacional de Deporte.

\footnotetext{
a Universidade Federal do Mato Grosso do Sul Campo Grande, MS, Brasil.

b Universidade Estadual de Campinas, Faculdade de Educação Física, Campinas, SP, Brasil.
}

\section{*Autor correspondente:}

Dirceu Santos Silva

E-mail: dirceu_09@yahoo.com.br 


\section{INTRODUÇÃO}

O Plano Brasil Medalhas 2016 (PBM) foi lançado em setembro de 2012 pela ex-presidente Dilma Rousseff e teve como objetivo central alçar o Brasil, pela primeira vez na história, entre os 10 primeiros países nos Jogos Olímpicos e entre os cinco primeiros países nos Jogos Paralímpicos do Rio de Janeiro, em 2016 (Ministério do Esporte, 2012).

O PBM teve como proposta de ações a contratação de equipes técnicas multidisciplinares, a viabilização da participação de atletas em competições internacionais, a realização de treinamentos e intercâmbios internacionais e o fornecimento de equipamentos e materiais esportivos para o treinamento de atletas (Ministério do Esporte, 2012).

As ações políticas do PBM foram amparadas pela Lei no 12.395, de 16 de março de 2011, que criou o Programa Bolsa Atleta Categoria Pódio, sob a responsabilidade da Secretaria Nacional de Esporte de Alto Rendimento, do Ministério do Esporte (ME).

O PBM pode ser caracterizado como uma ação política de médio prazo que buscou antecipar o objetivo do Plano Decenal de Esporte e Lazer (PDEL), de colocar o Brasil entre os 10 primeiros países no quadro de medalhas nos Jogos Olímpicos e entre os cinco primeiros países nos Jogos Paralímpicos do Japão, em 2020. O PDEL foi elaborado durante III Conferência Nacional do Esporte (CNE), em 2010 (Ministério do Esporte, 2010; 2012).

Ambos os planos (PBM e PDEL) se inserem na agenda política dos grandes eventos esportivos internacionais que ocorreram no Brasil entre 2007 e 2016. Em relação ao investimento financeiro, o PBM buscou direcionar recursos públicos para o esporte de alto rendimento, com previsão orçamentária inicial de mais de 1 bilhão de reais (Ministério do Esporte, 2010; 2012).

O direcionamento de recursos públicos aos grandes eventos esportivos internacionais gerou uma série de debates e questionamentos sobre a participação do Estado no fomento ao esporte de alto rendimento. Ao considerar tais elementos, as seguintes indagações orientaram a construção deste artigo: quais os principais resultados obtidos pelo ME a partir do PBM 2016? Quais são os principais resultados de eficácia, eficiência e efetividade social do PBM 2016?

As questões de pesquisa serviram como ponto de partida para a análise do PBM a partir do referencial teórico do ciclo de políticas públicas (policy cycle). Embora existam variações, a metodologia de análise a partir do ciclo de políticas públicas inclui as seguintes etapas: construção da agenda política (agenda setting), análise e definição do problema, seleção, implementação, execução e avaliação (Howlett; Ramesh; Perl, 2009; Bridgman; Davis, 2003; Frey, 2000).

A etapa da avaliação consiste na mensuração e análise dos impactos produzidos na sociedade a fim de aferir se os objetivos propostos foram alcançados (Saraiva, 2007). A avaliação corresponde ao meio mais seguro para mensurar o nível de excelência de uma política pública e envolve três princípios básicos: a eficácia; a eficiência; e a efetividade social (Figueiredo e Figueiredo, 1986; Arretche, 2001; Belloni et al., 2007).

A avaliação por eficácia está relacionada à comparação entre os instrumentos e os objetivos iniciais explícitos de uma política pública e os seus resultados finais alcançados. A avaliação da eficiência busca analisar a menor relação custo e benefício para alcançar os objetivos de uma ação política, com ênfase na otimização dos recursos utilizados. A avaliação da efetividade social diz respeito à análise da relação entre a implementação e os resultados de uma política pública, expressa pelo resultado alcançado (Figueiredo e Figueiredo, 1986; Arretche, 2001; Sthephanou, 2005; Belloni et al., 2007).

A avaliação de políticas públicas tem demostrado sua relevância para o Estado e para a sociedade, já que, além de contribuir para o aprimoramento e desenvolvimento da própria política, contribui para a maior precisão das análises e decisões governamentais. Nesse sentido, estudos voltados à avaliação de políticas públicas podem subsidiar futuras decisões de agentes políticos (Howlett; Ramesh; Perl, 2009).

Vale destacar que as avaliações das políticas públicas de esporte são escassas (Arretche, 2001; Belloni et al., 2007) e, no caso do PBM 2016, a temática ainda não foi amplamente explorada. Desse modo, o artigo tem como objetivo analisar o PBM 2016, a partir da avaliação por eficácia, eficiência e efetividade social.

\section{METODOLOGIA}

A pesquisa foi realizada a partir do método descritivoanalítico, com ênfase na abordagem qualitativa. A técnica de análise documental qualitativa possibilitou a investigação das ações do PBM (Richardson et al., 1999).

A coleta de dados foi realizada a partir de um levantamento de documentos oficiais, legislação, editais e normas que regulamentam as ações políticas. Os documentos analisados foram: Constituição Federal Brasileira de 1998; Lei no 9.615, de 24 de março de 1998 (Lei Pelé); Lei n. 10.264, de 16 de julho de 2001 (Agnelo Piva); Lei n. 10.683, de 28 de maio de 2003; Decreto n. 4.668, de 9 abril de 2003 (estruturação do ME); Lei n. 10.891, de 9 de julho de 2004 (Lei da Bolsa Atleta); Decreto n. 7.529, de 21 julho de 2011 (restruturação do ME); Lei no 12.395, de 16 de março de 2011 (Lei 
Atleta Pódio); documento do PBM 2016; Edital no 3, de 17 de julho de 2013; documento sobre os Critérios de Entrada e Manutenção do Valor da Bolsa Programa Atleta Pódio; documentos oficiais das CNEs realizadas em 2004, 2006 e 2010.

Os dados relativos à questão orçamentária e sua execução foram obtidos nos relatórios do Siga Brasil, que possibilita o acesso aos dados do Sistema Integrado de Administração Financeira (SIAFI). O artigo tem o recorte temporal de 2012 a 2016, período que permitiu a análise da construção da agenda política, da definição do problema, seleção, implementação, execução e avaliação de ferramentas políticas do PBM.

A técnica utilizada para tabulação e interpretação dos dados foi a análise de conteúdo temática, que permitiu o recorte dos textos de acordo com os conteúdos mais significativos. As análises foram organizadas em três polos cronológicos: a pré-análise, que teve como objetivo tornar operacionais e sistematizar as ideias iniciais, ler e escolher a documentação; a exploração do material, que correspondeu à fase de aprofundamento na leitura e análise; e o tratamento dos resultados, a categorização e a inferência (Bardin, 2011). As categorias de análise foram escolhidas com base nos princípios de avaliação: eficácia, eficiência e efetividade social (Figueiredo e Figueiredo, 1986; Arretche, 2001; Belloni et al., 2007).

\section{AGENDA POLÍTICA E IMPLEMENTAÇÃO DO PLANO BRASIL MEDALHAS 2016}

A elaboração de uma agenda política depende da existência de diversos temas e projetos que disputam espaço nas ações governamentais. A seleção e a definição de problemas, bem como as alternativas e soluções têm um potencial de conflito, que envolve o Estado, mídias e sociedade. Assim, os problemas que despertam maior atenção passam a fazer parte de um rol específico de temas com grandes chances de se concretizarem em ação do Estado (Kingdom, 2007; Brasil e Capella, 2015).

No que tange o aspecto normativo (polity), a agenda política esportiva no Brasil ganhou ênfase a partir da promulgação da Constituição Federal Brasileira de 1988. Nesse sentido, o artigo 2170 aponta que: “É dever do Estado fomentar práticas desportivas formais e não-formais, como direito de cada um" (Brasil, 1988).

No aspecto normativo, pode-se destacar ainda a promulgação da Lei $n$ ㅇ 9.615 , de 24 de março de 1998 (Lei Pelé), que definiu as dimensões esportivas: esporte de rendimento, praticado com regras nacionais e internacionais, com a finalidade de obter resultados; esporte de participação, praticado de forma voluntária, com o objetivo de contribuir para integração dos praticantes, promoção de saúde e educação; e esporte educacional, praticado nos sistemas de ensino, com o objetivo de alcançar o desenvolvimento integral do indivíduo e sua formação para a cidadania (Brasil, 1998).

A dimensão do esporte de rendimento teve seu orçamento expandido a partir dos anos 2000. Destacase a Lei no 10.264, de 16 de julho de 2001 (Lei Agnelo Piva), sancionada pelo ex-presidente Fernando Henrique Cardoso, que garantiu $2 \%$ da arrecadação de todas as loterias federais do Brasil para o esporte. Do total de $2 \%$ arrecadado, $85 \%$ passou a ser direcionado ao Comitê Olímpico Brasileiro (COB) e 15\% ao Comitê Paralímpico Brasileiro (CPB) (Brasil, 2001). Dois anos depois, em 2003, foi criado o ME, estruturado inicialmente em quatro secretarias nacionais: Secretaria Executiva; Secretaria Nacional de Esporte Educacional; Secretaria Nacional de Desenvolvimento de Esporte e Lazer; e Secretaria Nacional de Esporte de Alto Rendimento (Brasil, 2003a; Brasil, 2003b).

No entanto, O ME foi restruturado por meio do Decreto no 7.529 de 21 de julho de 2011, com seguintes secretarias: Secretaria Executiva; Secretaria Nacional de Esporte de Alto Rendimento; Secretaria Nacional de Esporte, Educação, Lazer e Inclusão Social; e Secretaria Nacional de Futebol e Defesa dos Direitos do Torcedor (Brasil, 2011a). Tal alteração na configuração das secretarias, segundo Silva, Borges e Amaral (2015), dizem respeito a opção política, decorrente da agenda política dos megaeventos esportivos no Brasil, que privilegiou o modelo esportivo de alto rendimento.

A partir da criação da instituição do $\mathrm{ME}$, o processo de formação da agenda esportiva foi marcado por uma arena de atores com diferentes discursos e argumentações na formação dos programas esportivos, comum em outras áreas das políticas públicas, conforme discutido por Kingdom (2007) e Brasil e Capella (2015). Dessa forma, diversos programas passaram a fazer parte da agenda política, dentre eles, o Programa Bolsa Atleta, criado por meio da Lei no 10.891, de 9 de julho de 2004, sancionada no governo do ex-presidente Luiz Inácio Lula da Silva. A bolsa tem uma variação de acordo com a categoria do atleta: Bolsa-Atleta Categoria Base e Bolsa-Atleta Categoria Estudantil (recebe o valor mensal de R\$370,00); BolsaAtleta Categoria Nacional (recebe R\$ 925,00); BolsaAtleta Categoria Internacional (recebe R\$ 1.850,00); e Bolsa-Atleta Categoria Olímpico e Paralímpico (recebe $\mathrm{R} \$ 3.100,00)$ (Brasil, 2004).

O Estado brasileiro assumiu um papel de regulador em relação ao setor esportivo. A sanção da Lei no 12.395, de 16 de março de 2011 (Lei Atleta Pódio) (Brasil, 2011b), evidencia a característica 
de regulação, bem como do direcionamento de recursos para o alto rendimento, e expansão do Programa Bolsa Atleta.

A Lei no 12.395, de 16 de março de 2011 (Lei Atleta Pódio) acrescentou duas categorias ao Programa Bolsa Atleta: categoria base (vinculado a uma entidade de prática esporte - clube) e categoria pódio (atletas classificados entre os vinte melhores do ranking da federação internacional). A categoria pódio foi o ponto central da nova legislação, e o atleta classificado e indicado pela a confederação passou a ter o direito a receber do poder público um montante, de no máximo, quinze mil reais mensais, durante um período de um ano (Brasil, 2011b).

De acordo com Silva, Borges e Amaral (2015) o Programa Bolsa Atleta busca o atendimento do acesso ao direito individual (do esporte como direito de cada um), uma vez que os benefícios são direcionados para os atletas de alto rendimento, que alcançam resultados significativos em âmbito nacional ou internacional, com a finalidade de melhorar a imagem do Estado.

O PBM foi além dos objetivos do Programa Bolsa Atleta a partir do momento que investiu em equipes multidisciplinares, na viabilização de sessões de treinamento no Brasil e no exterior, no fornecimento de equipamentos esportivos e no apoio financeiro ao atleta para participação em competições internacionais. A previsão orçamentária do Plano Plurianual 2012-2015 girou em torno de 2,5 bilhões de reais. Do montante total, 1,5 bilhão para o esporte de alto rendimento, e 1 bilhão para o PBM 2016 (610 milhões para o apoio ao atleta e 390 milhões para os centros de treinamento) (Brasil, 2011b).

A contratação de equipe multidisciplinar ocorreu com salários de até $\mathrm{R} \$ 5.000,00$. 0 orçamento para os equipamentos esportivos foi estipulado no valor $\mathrm{R} \$ 20.000,00$ anuais, e os centros de treinamento buscaram atender diferentes modalidades esportivas. Para o Governo Federal, o PBM foi condizente com a implementação e expansão das políticas públicas de esporte de alto rendimento. O Plano indicou a organização da ação do governo nos diferentes níveis: estratégico e tático (expansão de ações políticas) e operacional (expansão de orçamento) (Correia, 2016).

$\mathrm{Na}$ implementação do PBM foi notório o poder do $\mathrm{COB}$, do CPB e das Entidades Nacionais de Administração do Desporto (ENADs) no processo de indicação dos beneficiários do Programa Bolsa Atleta Pódio. Destacamse duas portarias que regulamentaram a indicação dos atletas: a Portaria ME no 67/2013, que estabeleceu os critérios para a seleção dos atletas e a Portaria ME no 103/2013, que criou os Grupos de Trabalho para a seleção dos atletas. A formação dos Grupos de
Trabalho envolveu o ME, O COB, O CPB, as Empresas Estatais e as Confederações. As principais dificuldades encontradas na indicação estiveram relacionadas à ausência de informações sobre os rankings e atletas, o que dificultou a interpretação de quem merecia receber a bolsa (Correia, 2016; Corrêa, 2016).

A partir da análise dos documentos foi possível identificar que a etapa organizacional envolveu o planejamento e a tomada de decisão (criação do PBM com o objetivo de médio prazo e a sanção da legislação vigente). A etapa processual correspondeu ao processo de trabalho da programação e monitoramento (criação dos Grupos de Trabalho, exigência do Plano Esportivo do Atleta e comprovação da possibilidade de medalha). A etapa comportamental diz respeito aos conflitos e aos processos de adaptação (dificuldades na implementação das equipes multidisciplinares, compra de equipamento e material esportivo específico, e criação ou reforma dos centros de treinamento). A última etapa foi a política, e correspondeu aos processos de poder das instituições e atores políticos (concentração de poder no COB, CPB e ENADs).

De acordo com Saraiva (2007) a implementação corresponde a fase de organização do aparelho administrativo, bem como dos recursos humanos, financeiros, materiais e tecnológicos para execução. No caso da presente pesquisa foi considerado o conjunto de ações políticas processadas para cumprir o objetivo do PBM.

\section{AVALIAÇÃO DO PLANO BRASIL MEDALHAS 2016}

A análise de políticas públicas contempla o processo de elaboração (formulação e implementação) e a fase de avaliação, que dedica o olhar sobre a relação entre os resultados esperados e os obtidos (Dagnino e Dias, 2007). Assim, o processo de avaliação política pode ser mensurado por meio da análise da eficácia, eficiência e efetividade social (Arretche, 2001; Schneider, 2010; Sthephanou, 2005).

No que diz respeito a análise por eficácia, a meta central do PBM consistia em colocar o Brasil entre os 10 melhores países no quadro de medalhas dos Jogos Olímpicos e entre os cinco melhores países nos Jogos Paralímpicos. No entanto, o resultado não foi alcançado e o Brasil ficou na 13ㅇ posição no quadro de medalhas dos Jogos Olímpicos, e na 80 posição no quadro de medalhas dos Jogos Paralímpicos, conforme Quadros 1 e 2.

Apesar da melhor colocação no quadro de medalhas e do maior número de atletas na delegação brasileira em uma única edição dos Jogos Olímpicos, pode-se afirmar que o PBM não foi eficaz diante do objetivo inicial. 
Quadro 1. Participação do Brasil nos Jogos Olímpicos.

\begin{tabular}{|lcccccc|}
\hline Jogos Olímpicos & Número de atletas & Ouro & Prata & Bronze & Total de Medalhas & Colocação Final \\
\hline 1988 Seul & 171 & 1 & 2 & 3 & 6 & 24 \\
1992 Barcelona & 197 & 2 & 1 & 0 & 3 & 25 \\
1996 Atlanta & 225 & 3 & 3 & 9 & 15 & 25 \\
2000 Sydney & 205 & 0 & 6 & 6 & 12 & 53 \\
2004 Atenas & 247 & 5 & 2 & 3 & 10 & 16 \\
2008 Pequim & 277 & 3 & 4 & 9 & 16 & 23 \\
2012 Londres & 259 & 3 & 5 & 9 & 17 & 22 \\
2016 Rio & 465 & 7 & 6 & 6 & 19 & 13 \\
\hline
\end{tabular}

Fonte: (COI, 2017).

Quadro 2. Participação do Brasil nos Jogos Paralímpicos.

\begin{tabular}{|lcccccc|}
\hline Jogos Paralímpicos & Número de atletas & Ouro & Prata & Bronze & Total de Medalhas & Colocação Final \\
\hline 1988 Seul & - & 4 & 9 & 14 & 27 & 26 \\
1992 Barcelona & - & 3 & 0 & 4 & 7 & 32 \\
1996 Atlanta & - & 2 & 6 & 13 & 21 & 37 \\
2000 Sydney & - & 6 & 10 & 6 & 22 & 24 \\
2004 Atenas & - & 14 & 12 & 7 & 33 & 14 \\
2008 Pequim & - & 16 & 14 & 17 & 47 & 9 \\
2012 Londres & - & 21 & 14 & 8 & 43 & 7 \\
2016 Rio & - & 14 & 29 & 29 & 72 & 8 \\
\hline
\end{tabular}

Fonte: (IPC, 2017)

Foi constatado que o maior número de medalhas olímpicas/paralímpicas, e a melhor classificação do Brasil no quadro de medalhas coincide com o período de expansão do orçamento do esporte de alto rendimento. No entanto, os resultados alcançados estão distantes do que foi planejado em curto prazo.

Correia (2006), ao aplicar questionário para 64 atletas olímpicos e 35 paralímpicos envolvidos com políticas oriundas do PBM, corrobora para expressar a ineficácia, já que $97 \%$ dos indicados receberam a bolsa pódio, $46 \%$ receberam apoio para participar de competições internacionais, $38 \%$ conseguiram apoio para montar a equipe multidisciplinar, e apenas $21 \%$ receberam equipamentos esportivos para o aperfeiçoamento do treinamento. Os centros de treinamento, por sua vez, só melhoraram as condições de $49 \%$ dos atletas.

A ineficácia de ações políticas do PBM está relacionada aos seguintes fatores: a ausência de critérios de avaliação do atleta; o fator impositivo da lei que obriga o atleta a estar classificado entre os vinte melhores do ranking internacional; o baixo envolvimento de algumas federações; a desconexão entre o ME, confederações e atletas; a dificuldade no preenchimento do Plano Esportivo pelos atletas; o atraso no pagamento das bolsas aos atletas; a inexistência de ferramentas para o monitoramento dos resultados de apoio aos atletas; e a excessiva burocracia (Correia, 2016).

Ao estudar o Bolsa-Atleta, Corrêa (2016) também apontou a ineficácia do PBM, sobretudo na concentração de poder nas Confederações Esportivas Nacionais, que definiu os critérios, atletas e competições passíveis de receberem a bolsa.

No que tange a eficiência desta política pública, que envolve o montante de recursos financiados e os resultados alcançados, verificou-se no Siga Brasil que entre os anos de 2013 e 2016, período de vigência do PBM, o Estado brasileiro direcionou 4,87 bilhões na Subfunção Desporto Rendimento ${ }^{1}$, o que equivale a $59 \%$ do orçamento do ME (Brasil, 2017).

Do ponto de vista orçamentário, o PBM teve um aporte de 1 bilhão de reais a mais de investimento público federal, entre 2013 e 2016, no esporte de alto rendimento. $\mathrm{O}$ orçamento do esporte foi originado de duas fontes: dois terços do Orçamento Geral da União (compõe o orçamento do ME e da Subfunção Desporto Rendimento) e um terço de empresas estatais, orçamento

${ }^{1}$ Entre 2013 e 2016 a Subfunção Desporte Rendimento obteve recursos exclusivamente do Ministério do Esporte, diferente de anos anteriores, em que o Ministério da Defesa também direcionou recursos. 
extraorçamentário. Desse montante de recursos, $\mathrm{R} \$ 690$ milhões foram direcionados ao apoio dos atletas e $\mathrm{R} \$$ 310 milhões foram destinados à construção de centros de treinamento (Ministério do Esporte, 2012).

Foram oito empresas estatais envolvidas no PBM (Banco do Brasil; Banco do Nordeste do Brasil; Banco Nacional de Desenvolvimento Econômico e Social; Caixa Econômica Federal; Centrais Elétricas Brasileiras $\mathrm{S} / \mathrm{A}$; Empresa Brasileira de Correios e Telégrafos; Empresa Brasileira de Infraestrutura Aeroportuária e Petrobras). O Termo de Cooperação entre as estatais e o ME foi assinado, no dia 13 de setembro de 2012. A vigência do contrato teve validade até dezembro de 2016 (Correia, 2016).

Deacordo com Pereira (2017) houve um crescimento significativo no Financiamento do Esporte por meio das estatais, aproximadamente de $591 \%$, entre os anos de 2004 e 2015. A criação do PBM marca o protagonismo das estatais como ator central no investimento do esporte de alto rendimento, conforme Gráfico 1.

A partir do Gráfico 1, pode-se afirmar que o PBM reforçou a relação entre empresas estatais e o esporte de alto rendimento. Pereira (2017) acrescenta que as estatais distanciaram do processo de democratização do esporte no Brasil, já que o gasto com a categoria Esporte de Alto Rendimento é significativamente superior que das outras categorias no orçamento geral do Ministério do Esporte.

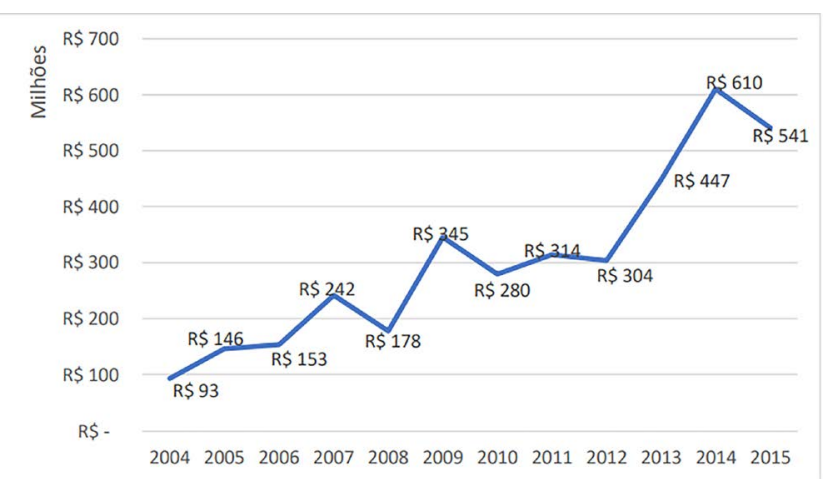

Gráfico 1. Financiamento esportivo das estatais entre 2004 e 2105. Fonte: (PEREIRA, 2017).

O apoio aos atletas e paraatletas envolveu o Programa Bolsa Pódio, que foi organizado a partir de quatro grupos: o 10 grupo (classificados entre o 10 e o 30 do ranking, bolsa de $15 \mathrm{mil} / \mathrm{mês}$ ); o 2 ㅇ grupo (classificados entre o 4ㅇ e o 8 o, bolsa de $11 \mathrm{mil} / \mathrm{mês}$ ); o 3 o grupo (classificados entre o 9o e o 16으, bolsa de $8 \mathrm{mil} / \mathrm{mês}$ ); e o 4 o grupo (classificados entre o 170 e o 20ㅇ, bolsa de $5 \mathrm{mil} / \mathrm{mês}$ ) (Ministério do Esporte, 2013a; 2013b).

Além das bolsas para os atletas e paraatletas, foram criadas outras modalidades como: a Bolsa Técnico ( $R \$ \$ 10 \mathrm{mil} / \mathrm{mês}$ ); a Bolsa equipe multidisciplinar (R\$
5 mil por profissional/mês); a Bolsa de equipamento e material esportivo ( $\mathrm{R} \$ 20$ mil por Atleta); e a Bolsa de apoio a treinamento no Brasil e no exterior e participação em competições (custo com diárias e passagens). 0 apoio à construção, reforma e operação de 22 centros de treinamento (21 olímpicos e 1 paralímpico), bem como aquisição de equipamentos esportivos (Ministério do Esporte 2012; 2013a).

O PBM apoiou 21 modalidades esportivas relacionadas aos Jogos Olímpicos (Atletismo; Basquete; Boxe; Canoagem; Ciclismo BMX; Futebol feminino; Ginástica artística; Handebol; Hipismo (saltos); Judô; Lutas; Maratonas aquáticas; Natação; Pentatlo moderno; Taekwondo; Tênis; Tiro esportivo; Triatlo; Vela; Vôlei e Vôlei de praia), e 15 modalidades esportivas relacionadas aos Jogos Paralímpicos (Atletismo; Bocha; Canoagem; Ciclismo; Esgrima em cadeiras de rodas; Futebol de 5; Futebol de 7; Goalball; Halterofilismo; Hipismo; Judô; Natação; Remo; Tênis de mesa e Vôlei sentado) (Ministério do Esporte, 2012).

Neste cenário, o Governo Federal, passou de um estado legislador do conteúdo da política (Constituição Federal Brasileira de 1988, Lei Zico e Lei Pelé) para um estado financiador por meio de um conjunto ações (Lei Agnelo Piva, Lei da Bolsa Atleta, Lei do Atleta Pódio e estatais). Dessa forma, os recursos foram direcionados para os atletas e paraatletas, ao buscar alterar qualitativamente as condições de treinamento.

Ao analisar o orçamento da Subfunção Desporto Rendimento, entre 2013 e 2016, verificou-se um crescimento do financiamento do esporte de alto rendimento (Gráfico 2). ${ }^{2}$

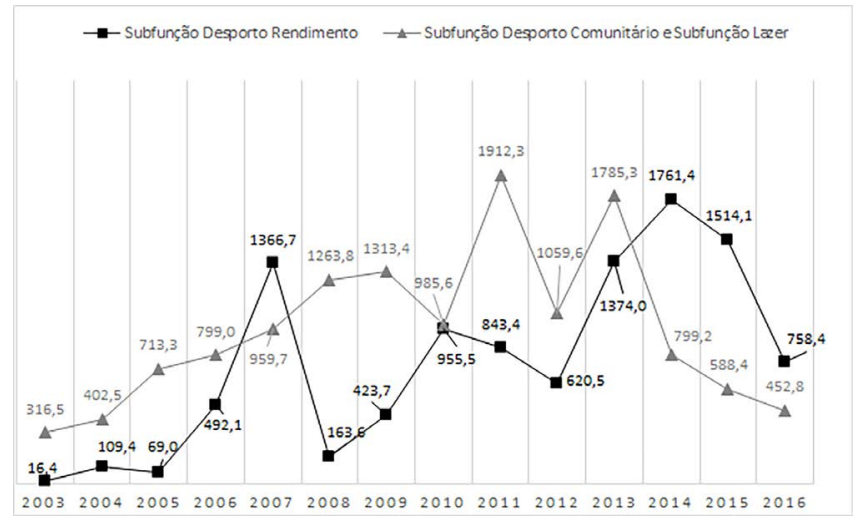

Gráfico 2. Comparação entre o orçamento das Subfunções Esporte Comunitário e Lazer e Subfunção Desporto Rendimento. Fonte: Portal Siga Brasil, Senado Federal. (Elaboração Própria).

A partir do Gráfico 2, pode-se afirmar que o PBM impactou no financiamento do esporte no Brasil, a partir do momento que os anos de 2014, 2015 e 2016

${ }^{2}$ Orçamentos executados, correspondentes ao ano 2016, corrigidos pelo IGP-DI, em milhões. 
tiveram um montante de investimento maior para Subfunção Desporto Rendimento em detrimento da Subfunção Esporte Comunitário e Lazer.

$\mathrm{Na}$ última categoria, efetividade social, por se tratar de uma política voltada ao esporte de alto rendimento, o PBM não mencionou a universalização das práticas esportivas e de lazer. Assim, a avaliação da efetividade social teve alcance limitado. A análise da execução orçamentária da Função Desporto e Lazer e suas subfunções corrobora com a análise de Silva, Borges e Amaral (2015), quando comprovaram a diminuição do aporte financeiro, para a Função Desporto e Lazer, nos períodos da realização dos megaeventos esportivos. É possível averiguar a mudança de agenda política do esporte no Brasil no acréscimo orçamentário para o alto rendimento no ano de 2007, com a realização dos Jogos Parapan-Americanos Rio de 2007, assim como, um acréscimo para a realização da Copa do Mundo de 2014 e Jogos Rio 2016. Ademais, é possível identificar que, ao longo da vigência do PBM (excetuando o ano fiscal de 2013), houve uma redução do orçamento do Desporto Comunitário e Lazer, que contemplam as dimensões do esporte de participação (como forma de lazer) e do esporte educacional.

Almeida e Marchi Júnior (2010) e Athayde, Mascarenhas e Salvador (2015) reportaram nas suas pesquisas uma predominância de investimentos para o esporte de alto rendimento no período no ano de 2007 em detrimento do esporte educacional e do esporte de participação. A prioridade nos recursos para o esporte de alto rendimento entra em conflito com a legislação brasileira, já que o princípio central foi a universalização do direito ao esporte e ao lazer.

Desse modo, pode-se afirmar que O PBM desconsiderou a questão da efetividade social, e colaborou para o esvaziamento do financiamento das dimensões do esporte de participação e esporte educacional. A ação política do ME enfatizou o apoio aos atletas que chegaram ao topo do rendimento esportivo. Ao analisar o plano dentro de um contexto macro de criação do $\mathrm{ME}$, pode-se afirmar que o PBM 2016 expandiu o orçamento para $\mathrm{O}$ alto rendimento.

\section{CONSIDERAÇÕES FINAIS}

O processo de avaliação é uma parte fundamental do ciclo político e busca oaperfeiçoamento/aprimoramento das ações futuras. Nesse sentido, as avaliações do PBM permitiram afirmar que o ME não alcançou de forma adequada a eficiência, a eficácia e a afetividade social, já que foi identificada uma distância entre o planejado e executado. O Plano não transformou o Brasil em uma potência olímpica e paralímpica no quadro de medalhas, conforme projetado, e contou com grande dispêndio de recursos públicos.
As considerações levantadas na pesquisa são relevantes para o campo das políticas públicas de esporte e lazer, uma vez que o ME contava com um Plano Decenal de Esporte e Lazer em processo, com o objetivo de colocar o Brasil entre os dez melhores países do quadro de medalha dos Jogos Olímpicos, e entre os cinco melhores países do quadro de medalha dos Jogos Paralímpicos de 2020, que será realizado no Japão.

Por fim, em um contexto de desmonte do ME, no ano de 2019, e criação de uma Secretaria Especial do Esporte, o Plano Decenal de Esporte e Lazer vigente pode ser impactado, o que demanda novas pesquisas para a área.

\section{REFERÊNCIAS}

Almeida BS, Marchi Júnior W. O Financiamento dos Programas Federais de Esporte e Lazer no Brasil (2004 a 2008). Movimento 2010 jul; 16 (4): 73-92.

Arretche MTS. Tendências no Estudo da Avaliação. In: Rico EM. (Org.). Avaliação de Políticas Sociais: uma questão em debate. 3.ed., São Paulo: Cortez, 2001. P.29-40

Athayde P, Mascarenhas F, Salvador E. Primeiras aproximações de uma análise do financiamento da política nacional de esporte e lazer no Governo Lula. RBCE 2015 jan; 36 (1): 2-10.

Bardin L. Content analysis. 5. ed., Lisbon, 2011.

Belloni I, Magalhães H, Sousa LC. Metodologia de Avaliação em Políticas Públicas: uma experiência em educação profissional. 4. ed., São Paulo: Cortez, 2007.

Brasil. Constituição (1988). Constituição da República Federativa do Brasil. Brasília, DF: Senado Federal; 1988.

Brasil. Lei n. 9.615, de 24 de março de 1998. Institui normas gerais sobre o desporto e dá outras providências. Diário Oficial da União 16 mar 1998; Seção 1, pt. 1.

Brasil. Lei n. 10.264, de 16 de julho de 2001. Acrescenta inciso e parágrafos ao art. 56 da Lei n. 9.615, de 24 de março de 1998, que institui normas gerais sobre o desporto. Diário Oficial da União 16 jul 2001; Seção 1, pt. 2.

Brasil. Lei n. 10.683, de 28 de maio de 2003. Dispõe sobre a organização da Presidência da República e dos Ministérios, e dá outras providências. Diário Oficial da União 29 mai 2003a; Seção 1, pt 2.

Brasil. Decreto n. 4.668, de 9 abril de 2003. Aprova a estrutura regimental e o quadro demonstrativo dos cargos em comissão e das funções gratificadas do Ministério do Esporte. Diário Oficial da União 10 abr 2003b; Seção 1, pt 2.

Brasil. Lei n. 10.891, de 9 de julho de 2004. Institui a bolsaatleta. Diário Oficial da União 2 jul 2004; Seção 1, pt1.

Brasil. Decreto n. 7.529, de 21 julho de 2011. Aprova a estrutura regimental e o quadro demonstrativo dos cargos em comissão e das funções gratificadas do Ministério do Esporte. Diário Oficial da União 22 jul. 2011a;. Seção 1, pt. 5

Brasil. Lei no 12.395 - Altera as Leis no 9.615 de março de 1998, que institui normas sobre desporto, e 10.891 de julho de 2004, que institui a Bolsa-Atleta e cria os Programas Atleta Pódio e Cidade Esportiva. Diário Oficial da União16 mar 2011b; Seção 1, pt. 1

Brasil. Siga Brasil: orçamento federal. [Acesso em 11 mar. 2019] Disponível em: <https://www12.senado.leg.br/orcamento/ sigabrasil> 
Brasil FG, Capella ACN. O processo de agenda-setting para os estudos das Políticas Públicas. Revista de Pesquisa em Políticas Públicas 2015;.6 [1]:41-63.

Bridgman P, Davis G. 'What Use is a Policy Cycle? Plenty, if the Aim is Clear' Australian Journal of Public Administration 2003 set; 62 [3]: 98-102.

Camargo JM. Política social no Brasil: prioridades erradas, incentivos perversos. São Paulo em Perspectiva 2004 jun; 18 [2]: 68-77.

Corrêa AJ. Autonomia da vontade das Confederações Esportivas no Programa Bolsa-Atleta: análise da legislação e suas relações. Curitiba. Dissertação [Mestrado em Educação Física] - UFPR; 2016.

Correia RL. Uma análise da formulação e dos processos de implementação do Plano Brasil Medalhas. Porto Alegre. Dissertação [Mestrado em Ciências do Movimento Humano] - UFGRS; 2016.

Dagnino R, Dias R. A política de C\&T Brasileira: três alternativas de explicação e orientação. Revista Brasileira de Inovação $2007 \mathrm{jul} / \mathrm{dez} ; 6$ [2]: 373-403.

Figueiredo MF, Figueiredo AMC. Avaliação Política e Avaliação de Políticas: Um Quadro de Referência Teórica. São Paulo: Idesp, 1986.

Frey K. Políticas públicas: um debate conceitual e reflexões referentes à prática da análise de políticas públicas no Brasil. Planejamento e Políticas Públicas 2000 jun; 1[21]: 212-259.

Howlett M, Ramesh M, Perl A. Studying Public Policy: Policy Cycles and Policy Subsystems. 3. ed. Don Mills: Oxford University Press. 2009

IOC (International Olympic Committee). The International Olympic Committee. [Acesso em 11 mar. 2019] Disponível em: <https://www.olympic.org/the-ioc>

IPC (International Paralympic Committee). Official Website of the Paralympic Movement [Acesso em 11 mar. 2019] Disponível em: <https://www.paralympic.org/results/historical>

Kingdon JW. Juntando as coisas. In: Saraiva E, Ferrarezi, Elisabete. (Org.). Políticas públicas: coletânea. Brasília, DF: ENAP, 2007. p. 225-245.

Ministério do Esporte. I Conferência Nacional do Esporte: documento final 2004 [Acesso em 11 mar. 2019] Disponível em: <http://www2.esporte.gov.br/conferencianacional/ conferencia1/documentoFinal.jsp>
Ministério do Esporte. II Conferência Nacional do Esporte: documento final 2006. [Acesso em 11 mar. 2019] Disponível em: <http://www2.esporte.gov.br/conferencianacional/ conferencia2/documentoFinal.jsp>

Ministério do Esporte. III Conferência Nacional do Esporte: documento final 2010. [Acesso em 11 mar. 2019] Disponível em: <http:// www2.esporte.gov.br/conferencianacional/resolucoesIIICNE.jsp>

Ministério do Esporte. Plano Brasil Medalhas 2016: Diretrizes do Plano 2012. [Acesso em 11 mar. 2019] Disponível em: <http://www.esporte.gov.br/index.php/institucional/altorendimento/plano-brasil-medalhas $>$

Ministério do Esporte. Edital no 3 de 17 de julho de 2013. Seleção pública de atletas a serem beneficiados pelo Programa Atleta Pódio no âmbito do Plano Brasil Medalhas 2016. Seleção pública 2013a. [Acesso em 11 mar. 2019] Disponível em: <http://www. esporte.gov.br/index.php/area-restrita/128-ministerio-doesporte/institucional/alto-rendimento/plano-brasil-medalhas>.

Ministério do Esporte. Critérios de Entrada e Manutenção do Valor da Bolsa Programa Atleta Pódio 2013b. [Acesso em 11 mar. 2019] Disponível em: <http://www.esporte.gov. br/arquivos/snear/brasilMedalhas/2016-12-22\%20-\%20 Critrios\%20de\%20Entrada\%20e\%20Manuteno\%20do\%20 Valor\%20da\%20Bolsa\%20Pdio.pdf>

Pereira, Claudia Catarino. As Empresas Estatais e o Financiamento do Esporte nos Governos Lula e Dilma. Brasília. Dissertação [Mestrado em Educação Física] - UNB; 2017.

Richardson RJ et al. Pesquisa social: métodos e técnicas. 3.ed. São Paulo: Atlas, 1999.

Saraiva E. Introdução à teoria política pública. In: Saraiva E, Ferrarezi, Elisabete. (Org.). Políticas públicas: coletânea. Brasília: ENAP, 2007. p. 21-42.

Schneider AL. Pesquisa avaliativa e melhoria da decisão política: evolução histórica e guia prático. In: Heidemann FG, Salm JF (Org.). Políticas públicas e desenvolvimento: bases epistemológicas e modelos de análise. 2 ed. Brasília: Editora Universidade de Brasília, 2010. p. 311-338.

Silva DS, Borges CNF, AMARAL SCF. Gestão das políticas públicas do Ministério do Esporte do Brasil. Revista Brasileira de Educação Física e Esporte 2015 mar; 29 [1]: 65-79.

Stephanou M. Análise comparativa das metodologias de avaliação das agências de fomento internacionais BID e BIRD em financiamentos de projetos sociais no Brasil. Revista Civitas 2005 jan/jun; 5 [1]: 127-160. 